\title{
CERIMÔNIAS DE ENCERRAMENTO EM TERAPIA INDIVIDUAL: EXPANDINDO OS SENTIDOS DA MUDANÇA
}

\author{
CLOSING CEREMONIES IN INDIVIDUAL THERAPY: \\ EXPANDING THE MEANINGS OF CHANGE
}

\begin{abstract}
PEDRO PABLO SAMPAIO MARTINS

Universidade de São Paulo - USP, Ribeirão Preto/SP, Brasil.
\end{abstract}

\section{MARINA ARANTES}

Instituto Verso: Mediação de Conflitos, Uberlândia, MG, Brasil.

Recebido em: 30/07/2018

Aprovado em: 16/09/2018
RESUMO: 0 construcionismo social chama atenção para o desafio de se levar, para além da sala de terapia, mudanças de sentidos que são construídas entre terapeuta e cliente. Sensível a essa problemática, este artigo tem como objetivo descrever as "cerimônias de encerramento", um formato de sessão utilizado na finalização de atendimentos individuais. A finalidade das cerimônias é construir uma história mais complexa acerca do processo de mudança em terapia, compartilhando-0 com pessoas externas a ela (testemunhas da vida pessoal do cliente e um terapeuta convidado). Quatro etapas guiam essa conversa terapêutica, respectivamente visando a: criar uma história sobre o processo; ampliar sentidos com a testemunha; transformar o lugar do terapeuta e construir um sentido social para 0 processo terapêutico. Trechos de uma cerimônia de encerramento são utilizados para ilustrar como esse formato informou as conversas práticas em um contexto interacional real, no qual perguntas, intervenções e modos de interação produziram efeitos específicos na conversa com uma cliente e sua testemunha. Refletimos sobre o caráter social das transformações individuais, discutindo a importância de os terapeutas produzirem práticas sensíveis à importância dos relacionamentos na construção e sustentação da mudança.

PALAVRAS-CHAVE: Construcionismo social; Terapêutica; Psicoterapia; Cerimônias de encerramento.
ABSTRACT: Social constructionism poses the challenge of how to take meanings which were constructed between therapist and client, to contexts beyond the therapy room. This article is sensible to this problem, and it aims to describe "closing ceremonies," which are a format of session that are used to finalize individual therapy. The aim of these ceremonies is to create a more complex story about the process of change in therapy, and to share this process with people who are not originally part of it (witnesses from the client's personal life, and an invited therapist). Four stages guide this therapeutic conversation, and they aim to: create a story about the process; expand meanings with the witness; change the place of the therapist; and, construct a social meaning for the therapeutic process. Excerpts of a closing ceremony are used to illustrate the way in which this format has informed practical conversations in a real interactional context, where questions, interventions, and ways of interacting have created specific effects in the conversation with a client and her witness. We reflect on the social character of individual change, and we discuss the importance of relationships in the construction and maintenance of change.

KEYWORDS: Social Constructionism; Therapeutics; Psychotherapy; Closing Ceremonies 
"E como eram as tranças?", perguntou Ugwu.

De início Olanna se espantou com a pergunta, depois percebeu que lembrava perfeitamente como o cabelo fora trançado, e começou a descrever o estilo penteado, com algumas trancinhas caindo sobre a testa. Depois descreveu a cabeça, os olhos abertos, o acinzentado da pele. Ugwu escrevia, enquanto Olanna falava, e o fato de ele escrever, a sinceridade de seu interesse, de repente fez sua história adquirir importância, a fez servir a um propósito maior, que nem mesmo Olanna sabia bem qual era...

(Chimamanda Ngozi Adichie, em

"Meio Sol Amarelo")

Quando a pessoa vive e compartilha com a outra, eu acho que deixa a pessoa mais forte. Quando acontecer algum problema... "Queria tanto falar com o Pedro (terapeuta) com relação a isso... Mas, quem será que pode me ajudar?" E eu me sinto nesse lugar, sabe? . . Então, acho que quando a pessoa vem aqui e sente na pele o que é, é muito melhor do que você abandonar no zero e aí ela um dia com um problema sentar e falar assim: "porque lá no Pedro, eu conversava com ele assim, assim e assim”. Entendeu? Agora eu já sei do que a gente está falando.

(Layla, em cerimônia de encerramento da terapia de sua irmã, Beatriz)

Os trechos acima foram retirados de contextos muito diferentes. O primeiro, de um livro de ficção, baseado na história real da guerra civil da Nigéria, nas décadas de 60 e 70 . O segundo, da transcrição de uma "cerimônia de encerramento" da terapia individual de Beatriz, uma jovem universitária de vinte e quatro anos de idade. Em comum, as duas passagens compartilham uma ideia central: nossas histórias pessoais se moldam e se sustentam, e ganham significado e relevância a partir de sua inserção em relacionamentos.

Neste artigo, lemos e interpretamos esses trechos a partir de uma compreensão construcionista social acerca das práticas terapêuticas (Lock \& Strong, 2012; McNamee, 2004). Deste lugar, buscamos contribuir com a reflexão sobre a importância dos relacionamentos na construção da mudança em terapia - especificamente, em terapia individual - ao descrever um formato de sessão que temos utilizado na finalização de muitos dos atendimentos individuais, em nossas clínicas particulares. Temos chamado a este formato de "cerimônias de encerramento". Nelas, além do terapeuta e do cliente, participam também um terapeuta convidado e testemunhas externas (pessoas que tenham relações significativas com o cliente).

Para responder ao nosso objetivo, delineamos este artigo da seguinte maneira: começamos mostrando o contexto teórico e prático - associado ao construcionismo social - no qual a proposta das cerimônias de encerramento faz sentido. A isso, segue-se a apresentação da proposta, considerando sua definição, participantes, inspirações e formato. Depois, trazemos os trechos de uma cerimônia de encerramento que gravamos, de uma cliente e sua irmã, para ilustrar como este formato informou as conversas práticas em um contexto interacional real. Por fim, oferecemos algumas reflexões sobre esta proposta, sobretudo no que diz respeito ao caráter so- 
cial das transformações individuais, e aos terapeutas como produtores de conhecimento.

\section{A CONSTRUÇÃO RELACIONAL DA MUDANÇA EM TERAPIA: POTENCIAIS E TENSÕES}

As práticas terapêuticas tipicamente associadas ao construcionismo social surgiram primeiramente no campo da terapia familiar. Este campo se desenvolveu a partir do questionamento do foco do tratamento em psicoterapia e saúde mental sobre o indivíduo, deslocando-o para os contextos e relações envolvidas nos sistemas familiares. A partir da década de 1980, o uso das ideias sistêmicas para o entendimento da própria atividade da terapia da comunicação e relacionamentos ocorrendo em sessão - produziu um terreno fértil para as propostas construcionistas sociais, com seu foco nos processos de produção de sentido e construção da realidade a partir dos relacionamentos (Paula-Ravagnani, Guanaes-Lorenzi, \& Rasera, 2017).

McNamee (2004) propõe um entendimento da terapia como uma construção social. Com isso, distancia sua discussão de uma preocupação com relação a quais modelos específicos estão sendo utilizados em uma prática, em direção a um interesse em compreender como os terapeutas trazem conceitos teóricos e formas de prática para o diálogo em terapia. A definição da terapia como conversa - como um contexto de produção de sentidos - é central a esse entendimento.

Para os construcionistas, a linguagem é ação. Quando descrevemos o mundo, atuamos ativamente sobre ele, criando possibilidades e limites a respeito de como podemos lidar com as coisas. Contudo, essas descrições não são produtos de mentes individuais, mas, sim, construídas em ação coordenada. Negociamos sentidos engajados em nossos relacionamentos cotidianos. Quem sou eu? Quem é meu interlocutor? Quem somos nós como família? Como entender uma situação específica que estamos vivendo? O que posso/podemos fazer com relação a ela? Essas perguntas - e quaisquer outras - só podem ser respondidas a partir de processos de construção de sentidos que nos permitem entender a nós mesmos, às nossas vidas, e ao mundo ao nosso redor de determinadas formas específicas (Lock \& Strong, 2012).

Quando algumas dessas formas de entendimento se mostram problemáticas ou conflituosas, causam sofrimento ou desconforto, paralisam ou reduzem as opções de ação - ou qualquer outro motivo socialmente legitimado como um "problema" -, a terapia oferece um contexto de relação que permite, por meio da conversa, negociações e transformações de sentido sobre esses mesmos entendimentos (Guanaes, 2006). Se linguagem é ação, ao mudarmos as descrições sobre algo (uma pessoa, uma relação, um problema, uma situação, etc.), mudamos também as possibilidades de ação sobre isso. Nessa conclusão reside o entendimento de que a terapia como conversa tem potencial transformador para as vidas das pessoas (Lock \& Strong, 2012; McNamee, 2004).

Contudo, reside nela também uma importante tensão teórica e prática. As formas tradicionais de terapia partem de um pressuposto do indivíduo autocontido (Sampson, 1993). De acordo com Brinkmann (2014), nessa forma de compreensão, a identidade é tomada como um fenômeno individual e relativamente estável, e as linguagens disponíveis para se descrever o sofrimento humano se apresentam 
em termos diagnósticos. Busca-se no indivíduo - seja em sua psique ou biologia - as causas das patologias e seus possíveis tratamentos. A partir dessa lógica, faz sentido a compreensão de que alguma mudança em terapia (tal qual conceituada por cada teoria) seria carregada pelo indivíduo para seus outros contextos e relações.

Porém, Gergen e Ness (2016) chamam a atenção para o fato de que isso não passa de uma pressuposição. Como vimos, o construcionismo social propõe uma série de transformações conceituais, com relação ao que significa ser alguém (Sampson, 1993), ao que é terapia (McNamee, 2004), e a como se constrói a mudança (Guanaes, 2006). Com isso, coloca de maneira relevante a questão de como levar, para além da sala de terapia, sentidos que são realizações relacionais.

Dito de outro modo, entender a terapia como construção social destaca a problemática de simplesmente acreditar que mudanças de sentido produzidas em terapia serão levadas para outros contextos da vida. Este questionamento sustenta-se sobre algumas transições conceituais. Primeiro, compreende-se os sentidos das coisas como uma realização social, e não como uma propriedade mental do indivíduo. Depois, reconhece-se que a produção desses sentidos está intimamente atrelada a contextos relacionais específicos, e não dada pelos fenômenos, objetos ou pessoas em si mesmos. Terceiro, afirma-se que sua sustentação é efêmera, dependente de suplementação social, e não estável e individual. A partir dessas compreensões, como podemos garantir que os sentidos negociados no setting terapêutico sejam sustentáveis e acionáveis para além daquela relação e contexto tão específicos da terapia
(Gergen \& Ness, 2016)? A sensibilidade a essa pergunta dá origem à proposta de cerimônia de encerramento que apresentamos neste artigo.

Felizmente, não estamos sozinhos no interesse em responder a essa preocupação. Ao longo das últimas décadas, muitas propostas surgiram interessadas em não naturalizar a ideia de que as transformações são individuais. Ao contrário, levam a sério a noção de que os sentidos precisam de sustentação social para ter implicações práticas. A título de ilustração e reflexão, citamos alguns exemplos bem-sucedidos dessas práticas. Para começar, o próprio campo da terapia familiar surgiu com base nesse questionamento, tanto conceituando os problemas, quanto atuando sobre eles, como partes de contextos de relações (Paula-Ravagnani, Guanaes-Lorenzi \& Rasera, 2017). No campo da saúde mental, Seikkula e Olson (2003) têm trabalhado com a noção de diálogos abertos, nos quais todas as pessoas da comunidade que sejam consideradas importantes na vida de alguém, participam da construção do tratamento diante de um episódio agudo de sofrimento mental.

Nessa mesma linha, Håkansson (2015) propõe a "sala de terapia estendida", na qual a ideia básica está em criar diferentes espaços - não apenas o cenário tradicional da terapia - no qual uma pessoa possa encontrar conversas significativas a partir das quais se sinta apoiada. Já a terapia social, conceitualmente, entende que não há uma separação entre transformação individual e social. Com isso, oferece contextos terapêuticos que têm início individual, mas com objetivo de se tornarem grupais, focados na performance e na ação social (Manfrim \& Rasera, 2016). No Brasil, a terapia comunitária integrativa (Barreto \& 
Grandesso, 2010) consiste de encontros em espaços públicos, abertos à comunidade, e oferecem oportunidades para as pessoas compartilharem coletivamente as múltiplas estratégias que utilizam para lidar com seu sofrimento. Visa à construção da coletividade, memória e ampliação de possibilidades focadas na comunidade, e não nos indivíduos.

Esses exemplos nos inspiram e certamente oferecem muitos recursos para os terapeutas refletirem sobre seus contextos de atuação. Em tais práticas, chama-nos atenção uma aposta em se transformar o próprio setting da terapia como resposta às mudanças conceituais promovidas pelo construcionismo social. Ao mesmo tempo em que admiramos essas transformações, notamos também que os formatos mais tradicionais de terapia - com um terapeuta e um cliente individual em um consultório particular - são ainda prevalentes nas práticas psicológicas, e um lugar cultural ao qual muitas pessoas recorrem ao buscarem ajuda para lidar com suas questões. Considerando este cenário específico, em nossa opinião, os melhores esforços de ampliação relacional de sentidos em terapia partem, sem dúvida, dos terapeutas narrativos.

Michael White (2012) e seus colegas oferecem uma série de "práticas de autenticação" em terapia. Essas propostas buscam construir legitimidade e reconhecimento para as mudanças dos clientes junto a pessoas importantes de suas vidas. Especificamente, a proposta de uma "cerimônia de definição" está intimamente ligada ao modo como concebemos nossas cerimônias de encerramento e, por isso, voltaremos a ela em detalhes mais à frente. Por ora, passamos a explicar nossa própria proposta de cerimônia de encerramento como mais uma forma de responder à questão do "transporte" do sentido construído em terapia individual para outros contextos.

\section{CERIMÔNIAS DE ENCERRAMENTO}

\section{Definição e Participantes}

Cerimônias de encerramento são sessões específicas que acontecem ao fim de um processo terapêutico com clientes individuais. Têm a finalidade de construir uma história mais complexa acerca do processo de mudança em terapia, que contemple as vozes não somente do cliente e do terapeuta responsável pelo caso, mas também de testemunhas importantes para a vida do cliente, bem como de outro profissional convidado. Ao se engajarem na tarefa de contar a história de um processo conversacional - da terapia, - um novo processo de negociação tem lugar, no qual sentidos compartilhados com pessoas externas ao processo original, mas socialmente legitimadas como importantes naquele contexto, podem facilitar seu acionamento para além daquele contexto.

Tipicamente, quatro pessoas participam de uma cerimônia de encerramento. O cliente é aquele que está em processo terapêutico há algum tempo, e chegou agora em um momento de finalização. O terapeuta regular é o profissional que acompanhou este cliente ao longo do processo. A testemunha é uma pessoa entendida pelo cliente como alguém importante em sua vida, e que poderia contribuir com seu progresso ao ouvir sobre o que se passou no processo terapêutico. Por fim, o terapeuta convidado é um profissional de confiança do terapeuta regular, que se junta à cerimô- 
nia de encerramento com a finalidade de conduzi-la a partir de um lugar de "estrangeiro", alguém que sabe pouco ou, preferencialmente, nada sobre a história do processo terapêutico. $\mathrm{O}$ número de participantes pode ser maior, dependendo da quantidade de testemunhas convidadas.

\section{Inspirações}

Como já mencionamos, nossa proposta está associada a preocupações específicas da literatura sobre terapia como construção social. Entendemos que ela tem como especificidade a proposta de um formato de conversa para a finalização da terapia individual. Ao mesmo tempo, ela é fortemente marcada por ideias advindas dessas outras propostas, às quais devemos muito em termos de inspiração. Trata-se, mais particularmente, de três ideias que atravessam nossas cerimônias de encerramento: as cerimônias de definição, de Michael White (2012), o conceito de dupla especialidade do encontro terapêutico, de Harlene Anderson e Harold Goolishian (1992), e os processos reflexivos, de Tom Andersen (1999).

\section{As Cerimônias de Definição}

As cerimônias de definição surgiram no contexto das práticas narrativas, com o objetivo de oferecer a oportunidade de as pessoas poderem falar sobre suas histórias de vida diante de audiências importantes para elas e, assim, desenvolver essas histórias de uma maneira enriquecida. Elas são organizadas em um formato de contar e recontar das histórias. O cliente conta sua história, que então é recontada pelas testemunhas convidadas. Por sua vez, então, o cliente recon- ta as histórias já recontadas. O foco da cerimônia está nos relatos, nas imagens e metáforas produzidas, no modo como as histórias ressoam pessoalmente para os interlocutores e na possibilidade de levá-las para outros contextos de vida (White, 2012).

Em grande medida, nossas cerimônias de encerramento são também cerimônias de definição. Devemos à proposta de Michael White a própria ideia de se produzir sessões no formato de cerimônias, o que lhes confere um caráter especial, diferenciado do restante do processo. Além disso, vem daí também nosso reconhecimento da importância de se convidar pessoas externas ao processo terapêutico para servirem como testemunhas dos relatos dos clientes, que possam legitimar e ampliar suas histórias. $\mathrm{O}$ formato de contar e recontar as histórias também nos inspirou a pensar um formato de cerimônia no qual cada etapa esteja intimamente conectada à anterior, produzindo reflexões sobre o que foi dito anteriormente. Contudo, acrescentamos e transformamos alguns desses elementos nas cerimônias de encerramento, pensando-as com objetivos específicos, bem como lhes incorporando elementos de outras propostas terapêuticas.

\section{A Dupla Especialidade no Encontro Terapêutico}

A ideia do encontro terapêutico como o encontro entre dois especialistas - um de conteúdo e outro de processo - é amplamente conhecida no campo da terapia como construção social. Ela foi articulada por Anderson e Goolishian (1992) e, originalmente, propõe que o cliente é o especialista sobre o conteúdo de sua própria vida, enquanto ao terapeuta cabe a especialidade de construção 
dos contextos conversacionais em sessão. Ao facilitar o processo de diálogo de determinadas formas, entende-se que a terapia funciona como um contexto de produção conjunta de sentidos, no qual a busca por "soluções" é colocada em suspenso, substituída pela curiosidade genuína do terapeuta, que ajuda o cliente a recontar suas histórias de maneiras diferentes, a partir de suas perguntas.

Essa ideia nos inspirou a pensar cada momento específico do processo reflexivo nas cerimônias de encerramento como sendo definido pela conversa entre um especialista do conteúdo e um do processo. Dessa forma, o terapeuta regular e o terapeuta convidado revezam-se como os especialistas do processo - como os "condutores" da conversa - enquanto a especialidade do conteúdo é revezada entre o cliente, sua(s) testemunha(s) e o próprio terapeuta regular, a depender do momento em questão. Criamos, assim, diferentes posições (Harré, 2015) a partir das quais os presentes podem falar, buscando a ampliação dos sentidos em sessão a partir de uma multiplicidade de perspectivas oferecidas pelos interlocutores nos diferentes momentos.

\section{Os Processos Reflexivos}

A ideia de processos reflexivos foi proposta originalmente por Tom Andersen (1999), um psiquiatra e terapeuta norueguês, a partir de sua prática com famílias. O conceito básico de um processo reflexivo é a construção de diferentes lugares de fala e escuta em uma conversa para os interlocutores presentes em uma interação. Não há um formato específico a ser seguido, mas sempre há a construção de espaços em que algu- mas pessoas podem falar, enquanto outras devem escutar. Segue-se a isso a mudança de lugares, em que a conversa subsequente sempre se dá em termos do que estava sendo dito na conversa anterior, ou seja, se produz uma nova conversa sobre a conversa. Em um processo de reflexão sobre o que estava sendo dito, os sentidos se ampliam e se transformam com a presença de interlocutores posicionados de maneiras específicas.

Pensamos nossas cerimônias de encerramento como um processo reflexivo em quatro etapas, nas quais há revezamentos entre posições de fala e de escuta em posicionamentos específicos (como especialistas de conteúdo ou de processo), a partir de momentos diferentes de conversa. Cada etapa se constitui como uma conversa sobre a conversa da etapa anterior, na qual se propõe ampliações a partir dos lugares de escuta específicos nos quais as pessoas estavam posicionadas anteriormente. Com isso, visamos a que uma história rica e ampla sobre o processo terapêutico do cliente possa ser construída, contemplando diferentes vozes.

\section{Formato}

Diante da possibilidade de término do processo, o terapeuta regular explica ao cliente a possibilidade de realizarem uma cerimônia de encerramento. Este convite pode se dar para qualquer cliente, mas, especialmente, é feito para aqueles que, por quaisquer razões específicas, estejam sentindo-se inseguros com a finalização, ou, ainda, que queiram compartilhar suas histórias com pessoas que participam mais proximamente de sua vida cotidiana. A cerimônia de encerramento acontece no mes- 
mo lugar da terapia individual e tem duração típica de uma hora e meia. A conversa tem início em uma roda, na qual o terapeuta regular apresenta brevemente a todos e explica novamente do que se trata aquela sessão e qual será o formato. Neste momento, existe um importante investimento na preparação das pessoas para estarem na conversa, a partir da ideia de que é preciso construir o contexto conversacional (Vicente, Japur, César, Ruffino, \& Russo, 2015).

Fazemos isso no formato de três pedidos para os participantes. Primeiro, lembramo-nos de que se trata de uma conversa pessoal, sobre assuntos íntimos e importantes de suas vidas e que, portanto, não há certo e errado nesta conversa, mas apenas contribuições e pontos de vista. Segundo, pedimos que participem da conversa de uma forma em que se sintam confortáveis. Explicitamente, dizemos que cada pessoa só precisa falar sobre aquilo que decidir ser importante naquele momento. Não há absolutamente nada que necessariamente tenha que ser dito. Por fim, pedimos que as pessoas participem na conversa a partir de um lugar de apreciação da experiência do outro. Com isso, queremos que elas estejam interessadas em conhecer a história e agregar a ela, evitando julgamentos e conselhos ao fazerem isso. Aos nossos pedidos como terapeutas, perguntamos também se os participantes gostariam de acrescentar outros, para que se sintam seguros e confortáveis naquela conversa.

Feitos os combinados sobre o contexto conversacional, criamos na sala dois sistemas - um de fala e um de escuta - delimitados pelos posicionamentos das cadeiras na sala. Algumas cadeiras são posicionadas em círculo no centro da sala. Este é o sistema de fala. Outras cadeiras são colocadas mais para o fundo da sala, geralmente perto de alguma parede, de modo que quem nelas estiver sentado possa observar as cadeiras do meio. Este é o sistema de escuta. Explicamos da seguinte forma: quem está sentado nas cadeiras posicionadas no meio da sala tem o direito de falar naquele momento. Quem está sentado nas cadeiras ao fundo da sala tem o direito de escutar. Explicamos que isso visa à criação de um revezamento e modos diferentes de participar da interação, de forma que todos tenham possibilidade de se expressar e serem ouvidos de maneira especial, em um ritmo de conversa diferente daquele do cotidiano.

A cerimônia acontece em quatro etapas. Cada etapa é composta pela conversa entre duas pessoas - uma tomada como especialista do conteúdo e outra como especialista do processo. As etapas têm objetivos específicos, diante do processo da cerimônia, e começam com perguntas disparadoras que têm como propósito facilitar uma conversa direcionada o suficiente para alcançar este objetivo, mas aberta o suficiente para que as pessoas possam encontrar suas próprias formas de participar. As características de cada etapa estão descritas na tabela na próxima página. 


\begin{tabular}{|c|c|c|c|}
\hline Etapa & $\begin{array}{l}\text { Especialidades } \\
\text { na Conversa }\end{array}$ & Objetivos & $\begin{array}{l}\text { Exemplos de } \\
\text { Perguntas } \\
\text { Disparadoras }\end{array}$ \\
\hline $\begin{array}{l}\text { Criando uma } \\
\text { história sobre } \\
\text { o processo } \\
\text { terapêutico }\end{array}$ & $\begin{array}{l}\text { Conteúdo: } \\
\text { Cliente } \\
\text { Processo: } \\
\text { Terapeuta } \\
\text { convidado }\end{array}$ & $\begin{array}{l}\text { Construir uma história } \\
\text { possível sobre o } \\
\text { processo terapêutico } \\
\text { com o cliente, que ele } \\
\text { entenda ser importante } \\
\text { compartilhar com sua(s) } \\
\text { testemunha(s). } \\
\end{array}$ & $\begin{array}{l}\text { O que você acha que } \\
\text { todas as pessoas nessa } \\
\text { sala precisam saber } \\
\text { sobre o processo que } \\
\text { você viveu junto do } \\
\text { Terapeuta Regular? }\end{array}$ \\
\hline $\begin{array}{l}\text { Ampliando } \\
\text { sentidos com a } \\
\text { testemunha }\end{array}$ & $\begin{array}{l}\text { Conteúdo: } \\
\text { Testemunha } \\
\text { Processo: } \\
\text { Terapeuta } \\
\text { regular }\end{array}$ & $\begin{array}{l}\text { Construir um espaço } \\
\text { de legitimidade para a } \\
\text { história do cliente, que } \\
\text { pode ser recontada e } \\
\text { ampliada a partir dos } \\
\text { entendimentos de sua } \\
\text { testemunha convidada. } \\
\text { Permitir que a } \\
\text { testemunha revisite sua } \\
\text { própria história a partir } \\
\text { da escuta da história do } \\
\text { cliente, funcionando } \\
\text { como uma "memória } \\
\text { relacional" do cliente. }\end{array}$ & $\begin{array}{l}\text { Do que você ouviu } \\
\text { o Cliente falar, o que } \\
\text { mais te toca? } \\
\text { Como você acha que } \\
\text { poderia lembrá-lo de } \\
\text { tal conquista caso ele } \\
\text { se esqueça? } \\
\text { Como essa história } \\
\text { ressoa em sua vida? }\end{array}$ \\
\hline $\begin{array}{l}\text { Transformando } \\
\text { o lugar do } \\
\text { terapeuta }\end{array}$ & $\begin{array}{l}\text { Conteúdo: } \\
\text { Terapeuta } \\
\text { regular } \\
\text { Processo: } \\
\text { Terapeuta } \\
\text { convidado }\end{array}$ & $\begin{array}{l}\text { Oferecer ao terapeuta } \\
\text { regular a possibilidade } \\
\text { de utilizar diferentes } \\
\text { vozes de seu próprio } \\
\text { diálogo interno para o } \\
\text { andamento da conversa. } \\
\\
\text { Dar visibilidade, para os } \\
\text { clientes, ao modo como } \\
\text { os terapeutas refletem } \\
\text { sobre suas conversas. }\end{array}$ & $\begin{array}{l}\text { Como você relaciona } \\
\text { a conversa até o } \\
\text { momento com o modo } \\
\text { como viveu o processo } \\
\text { com o Cliente? }\end{array}$ \\
\hline $\begin{array}{l}\text { Construindo } \\
\text { um sentido } \\
\text { social para } \\
\text { o processo } \\
\text { terapêutico }\end{array}$ & $\begin{array}{l}\text { Conteúdo: } \\
\text { Todos } \\
\text { Processo: } \\
\text { Terapeuta } \\
\text { convidado }\end{array}$ & $\begin{array}{l}\text { Produzir a ideia de que } \\
\text { os sentidos construídos } \\
\text { no processo terapêutico } \\
\text { - ainda que sejam } \\
\text { realizações conjuntas } \\
\text { de terapeuta e cliente } \\
\text { sobre as experiências } \\
\text { deste último - são } \\
\text { também sociais, e agora } \\
\text { compartilhados por este } \\
\text { grupo específico. }\end{array}$ & $\begin{array}{l}\text { Como foi para vocês } \\
\text { participar desta } \\
\text { conversa? O que mais } \\
\text { chama atenção? } \\
\text { Como isso promove } \\
\text { reflexões sobre suas } \\
\text { vidas? } \\
\text { Como imaginam que } \\
\text { essa conversa impacta } \\
\text { a relação de vocês? }\end{array}$ \\
\hline
\end{tabular}


Nossa História com Beatriz e Layla

Beatriz foi cliente de Pedro, primeiro autor deste artigo, em terapia individual por três meses. À época do atendimento, ela tinha vinte e quatro anos de idade, era estudante universitária, e chegou dizendo que tinha vários assuntos dos quais gostaria de cuidar. Dentre eles, especificamente, a relação com seus pais. Ela dizia ser muito diferente dos pais, em termos de valores e visões de mundo. Eles, mais conservadores; ela, mais liberal. Contudo, ela morava com os pais e sentia que suas opiniões importavam muito para ela, o que a deixava em conflito e sofrimento. Via-se muitas vezes dividida entre fazer o que acreditava e valorizava, ou se guiar pelos valores dos pais. Situações como esta se repetiam desde eventos cotidianos - na decisão sobre qual o tipo do vestido que usaria em seu baile de formatura, por exemplo - até outras mais sérias, como quais lugares seriam considerados "adequados" para ela frequentar ou não.

$\mathrm{O}$ atendimento foi encerrado a pedido dos pais de Beatriz, que pagavam pela terapia, e pediram pela suspensão por contenção de gastos. Beatriz se disse insegura para fazer o encerramento, pois sentia que havia apenas começado a "mexer com seu mundo" na terapia, e tinha medo de "retroceder" sem o apoio semanal. A cerimônia de encerramento foi proposta pelo terapeuta como resposta a essa preocupação. Ele explicou à cliente sobre seu funcionamento e função, propondo que ela convidasse a participar alguém em sua vida com quem gostaria de compartilhar a história que estava vivendo em terapia, e que também pudesse ajudá-la em seu cotidiano a se manter conectada com essa mesma história. Beatriz escolheu convidar
Layla, sua irmã mais nova, de vinte anos de idade. Explicou sua escolha baseada em duas razões: primeiro, por serem amigas e compartilharem proximamente a vida; segundo, porque a irmã também vivia muitos dos mesmos dilemas com os pais, tal como descritos por Beatriz. Marina, a segunda autora deste artigo, conduziu a cerimônia, a convite de Pedro, e com a concordância de Beatriz e Layla.

A cerimônia de encerramento aconteceu no consultório privado do primeiro autor, e teve duração de uma hora e meia. Esta sessão foi gravada com o consentimento de Beatriz e Layla, mediante explicação de que nós, terapeutas e autores, gostaríamos de utilizá-la como exemplo para publicação daquele formato de encerramento. Não se trata, portanto, de pesquisa empírica, mas, sim, de relato de experiência clínica, no qual utilizamos a transcrição da sessão como apoio para a construção do conhecimento. Combinamos de gravar a sessão e, ao final da mesma, discutir se as clientes aprovariam sua utilização, o que ocorreu com seu consentimento.

A sessão foi transcrita integral e literalmente. A leitura desta transcrição serviu como inspiração para refletirmos sobre nossa prática, em um trânsito de vai e volta entre, por um lado, as já citadas teorias que guiam a construção das cerimônias de uma determinada forma e, por outro, as especificidades de uma interação terapêutica real, na qual nossas perguntas, intervenções e modos de interação produziram efeitos específicos na conversa com Beatriz e Layla (O'Reilly, Kiyimba, \& Lester, 2018). Diante da escrita do artigo, entramos novamente em contato com as clientes, para que pudessem ler o manuscrito e sugerir mudanças, alterações e cortes na descrição da história aqui apresentada. Em seguida, a 
versão final foi aprovada pelas clientes, que tiveram seus nomes alterados para preservação de sua identidade.

A cerimônia de encerramento aconteceu em quatro etapas. A seguir, descrevemos nosso entendimento do que se trata cada uma dessas etapas, buscando explicitar seus principais objetivos, perguntas disparadoras, posicionamentos dos interlocutores e modos mais típicos de interação. Os trechos de transcrição da cerimônia de encerramento de Beatriz são utilizados para exemplificar cada uma das etapas e fornecer elementos concretos de como a interação terapêutica se desenvolveu naquele contexto.

Etapa 1: criando uma história sobre 0 processo terapêutico

Marina (terapeuta convidada): $o$ que você acha importante que eu, a Layla... Todo mundo que está aqui na sala, saiba sobre o processo terapêutico que você viveu com o Pedro?

Beatriz (cliente): acho que o mais importante é que... Tudo isso que eu estou construindo aqui, que eu estou aprendendo e levando pra minha vida, é... Mexeu muito com meu mundo, sabe?... Eu estava na zona de conforto, às vezes eu sofria com algumas coisas, mas eu não sabia muito que fazer. A gente tocou só em algumas partes que teve a ver com a minha família. Do meu relacionamento com meu pai e minha mãe. A gente é muito diferente. O jeito deles é muito tradicional... E eu não consigo me ver nisso. Mas, só que a opinião deles importa demais pra mim. De um tanto que me faz sofrer. Quando eles não gostam da minha tatuagem. Do jeito que eu me visto.
E agora... Isso está mudando, sabe? Antes, eu só conseguia ficar triste. A única reação minha era chorar. E ficar no meu canto. Nem falar com eles alguma coisa eu conseguia. Mas, agora, eu já consigo entender que o elogio que o meu amigo me faz pode ser tão importante quanto a crítica que minha mãe faz, entendeu? É por aí assim.

O trecho acima mostra o início da cerimônia de encerramento do processo terapêutico com Beatriz. Na sala, os participantes estão posicionados em dois sistemas diferentes, um de fala e um de escuta. Na primeira etapa, o terapeuta convidado é entendido como o especialista do processo, aquele responsável pela condução do diálogo; enquanto o cliente é o especialista do conteúdo a ser conversado. O terapeuta regular e a testemunha ficam sentados nas cadeiras ao fundo da sala. Essa etapa tem como objetivo construir uma história possível sobre o processo terapêutico com o cliente, que ele entenda ser importante compartilhar com sua(s) testemunha(s).

Duas questões são dignas de nota quanto a essa etapa. Primeiro, não se trata de uma retomada exaustiva do processo terapêutico, nem de uma avaliação do mesmo. O mais importante é que o cliente e o terapeuta convidado possam, juntos, explorar uma história inteligível sobre o processo daquilo que o cliente ache mais marcante, importante e se sinta confortável em compartilhar. Por isso, a pergunta inicial do terapeuta convidado é aberta. Segundo, o terapeuta regular evita ao máximo compartilhar previamente com o terapeuta convidado aspectos sobre o processo do cliente. Esse cuidado visa a facilitar que o terapeuta convidado possa participar da conversa a partir de uma posição de 
"estrangeiro" ao conteúdo, apegando-se à versão da história entendida como relevante para o cliente, e não para seu colega terapeuta. Acreditamos que essa posição facilita a exploração de uma história que valorize as metáforas e entendimentos do cliente como especialista de sua própria vida (Anderson \& Goolishian, 1992).

Como vemos no trecho, Beatriz responde à pergunta indo de uma questão abstrata e geral "a terapia mexeu com o meu mundo", para um recorte específi$\mathrm{co}$, que tem a ver com sua relação com seus pais. Neste recorte, Beatriz conta uma narrativa de progresso, saindo de uma posição inicial na qual se sentia sem opções de ação e em sofrimento, em direção a uma posição na qual reconhece as vozes de outros interlocutores como importantes na construção do seu senso de si e, portanto, em suas possibilidades de agir.

A primeira etapa tem fim quando terapeuta convidado e cliente entendem que o delineamento inicial da história construído entre eles já é uma versão suficiente para o entendimento de todos os presentes. Neste momento, o terapeuta convidado propõe que os sistemas troquem de lugar, de modo que quem estava sentado nas poltronas centrais vai para as do canto, e vice-versa. Tem início, assim, a segunda etapa da cerimônia de encerramento.

\section{Etapa 2: ampliando sentidos com a testemunha}

Pedro (terapeuta regular): o que mais te chamou atenção no relato da Beatriz? O que mais te toca? O que você fica com vontade de falar sobre?

Layla (testemunha): aqui, eu já vejo uma Beatriz mais presente. Já vejo ela mais segura. Muito mais segura...
Personalidade. Uma pessoa que tem amigos. Ela continua sendo ela mesma. Só que agora, você vê isso muito mais nítido. Uma força de correr atrás das coisas dela. De falar: quero isso, quero aquilo, não gosto disso.

Pedro (terapeuta regular): como ver essa Beatriz diferente... Como isso mexe com você mesma? Isso te ensina alguma coisa?

Layla (testemunha): ensina muito. Quando ela fala com relação à minha família, é um pouco de decepção... e acho que talvez seja aí uma guerra perdida.

Pedro (terapeuta regular): faz diferença pra você, no meio dessa guerra, ter uma companheira mais forte?

Layla (testemunha): nossa. Horrores (começa a chorar). Agora ela está se mudando de cidade. E aí eu sempre fico pensando... Chorei de soluçar esses dias. O que eu vou fazer sem a Beatriz? ... A Beatriz consegue argumentar, falar, enxergar o que está certo e o que está errado... Vejo ela com um papel muitíssimo importante na minha vida.

$\mathrm{Na}$ segunda etapa da cerimônia de encerramento, o terapeuta regular é o especialista do processo, e a testemunha é o especialista do conteúdo. Esta etapa tem como objetivo principal construir um espaço de legitimidade para a história do cliente, que pode ser recontada e ampliada a partir dos entendimentos de sua testemunha convidada.

Como vemos no trecho acima, a pergunta de abertura desta etapa é também aberta. Inspirados por Shotter (2015), perguntar sobre o que chama atenção no relato e como a história 
toca a testemunha visa a afastá-la de uma posição de "checagem" da história anterior e convidá-la a produzir um relato pessoal de sua própria experiência ouvindo a história de alguém querido. As histórias aqui se misturam, e a testemunha pode funcionar como uma "memória relacional" do cliente; alguém com quem viveu experiências marcantes, e que sabe de versões importantes de sua história, das quais poderão se lembrar juntos em outros contextos de suas vidas cotidianas (White, 2012). Além disso, ao criar para a cliente um lugar de escuta sobre sua própria história, ela é posicionada como alguém que tem algo a oferecer, ensinamentos a compartilhar, o que é diferente da posição mais típica de dificuldades e falta de opções a partir da qual as pessoas tipicamente costumam procurar a terapia.

A primeira parte da conversa entre Pedro e Layla mostra o recontar de uma versão segura sobre Beatriz, como alguém que sabe o que quer e contempla suas próprias opções diante da vida. Na pergunta seguinte, Pedro convida Layla a refletir sobre como essa história impacta sua vida. Isso dá espaço para um relato emocionante no qual Layla se posiciona também como alguém que sofre com a mesma questão familiar, e que encontra nessa Beatriz diferente uma possibilidade de apoio para suas próprias questões. Além disso, na segunda parte da conversa, Pedro pergunta sobre o que Layla aprende com o relato de Beatriz, o que posiciona a cliente como alguém que tem algo a ensinar. Com sua resposta, Layla ajuda na construção de uma Beatriz muito habilidosa, alguém com um bom julgamento, e que sabe conversar e argumentar. Nestes termos, constroem um entendimento de que as duas estão vivendo juntas um dilema inicialmente trazido por Bea- triz, e que sua mudança não apenas é legitimada por Layla, mas também muito importante em seu próprio modo de viver.

Etapa 3: transformando o lugar do terapeuta

Marina (terapeuta convidada): $P e$ dro, eu queria saber, do que você ouviu aqui... Do que a Beatriz disse, do que a Layla trouxe... Que diferença isso faz pra você, quando você conecta essa conversa com o processo que vocês viveram aqui na terapia?

Pedro (terapeuta regular): é ouvir essa outra Beatriz, que eu já via como potencial, na voz de outra pessoa, da Layla, e principalmente de ouvir essa Beatriz na voz da própria Beatriz. Então, isso pra mim faz muita diferença... O que mexe comigo é que é muito legal você ouvir as suas palavras na boca de outra pessoa... E o tanto que a gente escothe na nossa cabeça com que vozes a gente vai conversar. E isso é mais uma coisa que me dá mais um senso de tranquilidade, de que a Beatriz parece que sacou o tipo de coisa que a gente conversava aqui... E ela já sabe falar para ela mesma algumas coisas que a gente conversa, e isso é arrepiante.

Na terceira etapa da cerimônia de encerramento, os participantes se reposicionam novamente. Dessa vez, cliente e testemunha ficam no sistema de escuta, enquanto o terapeuta convidado entrevista o terapeuta regular sobre suas impressões e vivências naquela conversa específica, conectando-as também com outras reflexões vividas ao longo da terapia. O objetivo 
desta conversa é oferecer ao terapeuta regular a possibilidade de utilizar diferentes vozes de seu próprio diálogo interno para o andamento da conversa (Rober, Elliott, Buysse, Loots \& De Corte, 2008), sobretudo no que diz respeito a fortalecer descrições que considere, a partir do processo terapêutico como um todo, importantes para o senso de si do cliente. Esse tipo de autorrevelação do terapeuta não diz respeito a alguma "confissão", mas de falar sobre aspectos específicos das vivências do terapeuta que tipicamente não são o foco da sessão, e utilizá-las a favor do desdobramento da conversa (Martins \& Guanaes-Lorenzi, 2017). Criamos, assim, a oportunidade de os clientes ouvirem como os terapeutas refletem sobre suas conversas, além de desfocar a figura do terapeuta como "especialista" e "neutro", mas como alguém que também se afeta, de forma corporificada, pelas conversas vividas em terapia (Andersen, 1999; Shotter, 2015). Apesar de menos socialmente valorizada do que a fala, a escuta também é um lugar de transformação, pois faz parte ativamente da construção conjunta de sentidos em qualquer interação (McNamee, 2004).

$\mathrm{Na}$ conversa entre Marina e Pedro, o terapeuta regular escolhe contar sobre como ouviu, durante aquela sessão, a história de Beatriz em diferentes vozes, e como isso produz para ele um senso de que aquela história não pertence apenas a um indivíduo isolado, mas é parte de um processo social. Ouvir suas palavras na boca de outra pessoa, escolher com quem quer conversar e saber falar para si mesmo algo que alguém um dia falou são todos conceitos que chamam atenção para a construção dialógica e relacional da mudança (Guanaes, 2006) e funcionam para reforçar que Beatriz não está sozinha em sua caminhada.
Etapa 4: construindo um sentido social para o processo terapêutico

Marina (terapeuta convidada): nesse momento, eu e o Pedro pensamos em fazer em roda... Eu queria saber, Beatriz, como isso ressoou em você, o que você pensou sobre você e o processo que você viveu aqui.

Beatriz (cliente): então, primeiro pelo que a Layla falou. Parece que ela estava falando de outra pessoa! Que não sou eu, sabe? Parece que... É uma pessoa tão assim que eu não sabia que eu tinha toda essa influência, esse poder, assim. Mas, foi muito positivo, eu concordo, apesar de não conseguir enxergar tanto isso que ela falou. Mas... É uma responsabilidade que vem com isso que ela fala. Não é só aqui, só o meu mundo que está balançando por causa do que eu estou vivendo aqui. $O$ dela também. Lá em casa também... Agora... Sobre o que o Pedro falou... Eu acho que tem um pouco mais de conexão do que eu penso, com o que você falou, Pedro. Não é tão diferente assim ouvir que nem a Layla.

Marina (terapeuta convidada): Layla, você imaginava que ela ia perceber essa diferença? Que seria uma surpresa pra ela?

Layla (testemunha): eu imaginava.... Por ela sempre ficar em segundo plano. Agora, quando ela escuta alguém falando dela de primeiro plano tão forte... Reconhecendo essa fortaleza que ela é. Acho que ela não está acostumada ainda. Eó, acho que é preciso ela se acostumar urgentemente!

Na última etapa da cerimônia de encerramento, os dois sistemas - fala e escuta - se juntam em um único, no qual 
podem conversar sobre a experiência vivida ao longo daquela sessão. $\mathrm{O}$ terapeuta convidado retoma sua posição de especialista do processo, conduzindo o contexto conversacional de modo que todos os participantes possam conversar entre si sobre aspectos daquele momento que considerem relevantes. Esta etapa tem como objetivo principal costurar a ideia de que os sentidos construídos no processo terapêutico - ainda que sejam realizações conjuntas de terapeuta e cliente sobre as experiências deste último - são também sociais, e agora compartilhados por este grupo específico. Conferimos explicitamente, assim, um sentido social para o processo terapêutico individual (Gergen \& Ness, 2016; White, 2012).

No caso da cerimônia com Beatriz e Layla, Marina iniciou esta etapa enquadrando o último momento da conversa como sendo "em roda", de modo a incluir as vozes de todos os participantes. Começou direcionando a conversa para que Beatriz pudesse refletir em voz alta sobre como todas as conversas anteriores ressoavam para ela. É curioso notar como Beatriz explica que a descrição de Layla sobre ela foi muito diferente do que ela estava acostumada. Contudo, esta parece ser uma diferença adequadamente incomum (Andersen, 1999), ou seja, uma descrição que não é igual àquelas mais típicas às quais alguém está acostumado, mas diferente o suficiente para produzir reflexão. $\mathrm{Na}$ voz de Layla, Beatriz se vê mais poderosa e influente do que imaginava. Além disso, chama atenção para como a mudança em "seu mundo" (uma mudança tomada inicialmente apenas como interna) não é apenas sua, mas repercute também para Layla e em sua vida familiar.

Por outro lado, Beatriz descreve que se ouvir como uma pessoa potente na voz de Pedro parece mais conectado com o que já sabia sobre si. Isso mostra como as descrições dependem das relações nas quais se produzem: a versão de Beatriz descrita pelo terapeuta é um produto de suas interações naquele contexto e, portanto, mais conhecidas e legitimadas. Acompanhados de toda a literatura construcionista social sobre o self e a mudança (por exemplo, Gergen, 2009; Harré, 2015), não se trata de encontrar qual é a descrição mais verdadeira ou correta de Beatriz, mas entender que, em meio a essas possibilidades, ela pode agora entender a si mesma de formas mais complexas e, quem sabe, buscar diferentes ações.

Quando Marina pergunta para Layla se ela se surpreendeu com a resposta de Beatriz, o que a testemunha faz com sua fala é legitimar que sua descrição é mesmo diferente das mais comuns utilizadas por sua irmã e, reitera, potencialmente mais útil em alguns de seus contextos cotidianos. De uma forma ou de outra, como Layla disse no trecho com o qual iniciamos este artigo, ela e a irmã agora compartilham histórias sobre Beatriz às quais podem se referir em sua vida sem ter que recomeçar do zero qualquer conversa de potencial ajuda para ela. Consolida-se, assim, o sentido social da mudança de Beatriz. A partir deste sentido, Layla se torna uma testemunha que pode ajudar Beatriz a relembrar de conversas importantes que, anteriormente, existiam apenas no contexto da terapia. Pode, ainda, ser uma importante interlocutora na continuidade das transformações desses sentidos na vida como um todo.

\section{REFLEXÕES FINAIS}

No trecho de "Meio Sol Amarelo" com o qual abrimos o artigo, a romancista Chimamanda Ngozi Adichie 
descreve de maneira muito sensível o modo como o interesse de um interlocutor pelo contar de uma história - sua postura, suas perguntas, suas ações confere importância e propósitos específicos até então inexplorados para esta mesma história. Em nossas cerimônias de encerramento, acreditamos na construção de contextos especiais de conversa, nos quais histórias surgidas da relação terapeuta-cliente possam encontrar novos e importantes interlocutores que as ampliem, as fortaleçam e as mantenham vivas e importantes para além das paredes da clínica e das reflexões individuais do cliente. Com a história de Beatriz e Layla, esperamos ter ilustrado, no contexto de uma interação terapêutica, uma possibilidade de como essa construção se dá a partir de nossa proposta.

Com a palavra "possibilidade", chamamos atenção para o fato de que nossa descrição das cerimônias de encerramento não trata de um modelo fixo ou receita. Ao contrário, apostamos em sua descrição como mais uma inspiração, uma forma de organizar o processo reflexivo que tem nos sido muito útil, mas que, reconhecemos, pode e deve ser transformada de acordo com cada contexto específico de interação. Apenas para ilustrar, nas demandas cotidianas da vida profissional - bem como das vidas pessoais dos clientes - já realizamos cerimônias em que o terapeuta convidado atuou também como testemunha do processo, e outras sem a presença de um terapeuta convidado. Além disso, pensamos como sugestão muito potente a ideia de utilizar as cerimônias ao longo da terapia tanto em momentos de saltos qualitativos, quanto em avaliações do processo terapêutico. A construção do contexto conversacional, a preparação das pessoas para estar em diálogo, a postura de construção conjunta do espaço terapêutico, bem como o entendimento do caráter relacional da mudança são os focos da cerimônia e, portanto, muito mais importantes do que seu formato específico ou qualquer pergunta disparadora.

Neste contexto, compreendemos a cerimônia de encerramento como mais um contexto de produção de sentidos na vida dos clientes. Com isso, destacamos que não se trata de uma conversa de busca de alguma verdade estável sobre as pessoas, mas de mais uma experiência na qual seus entendimentos sobre si e sobre sua vida podem continuamente ser negociados. O sentido está sempre em movimento, sempre dependente das próximas interações, e nisso reside a potência das interações humanas - tanto em terapia, quanto no cotidiano.

Gostaríamos de finalizar este artigo com uma nota sobre a solidariedade entre terapeutas que se faz presente nas cerimônias de encerramento. Entendemos que a terapia é uma atividade frequentemente solitária para os profissionais - sempre acompanhados de clientes e pacientes, com poucas oportunidades de troca com outros profissionais. Em nossas próprias histórias como terapeutas, temos entendido as cerimônias de encerramento como oportunidades muitos especiais de trabalharmos juntos e construirmos novas possibilidades de atuação. Entre nós, temos uma fala recorrente - em tom de brincadeira - de que somos terapeutas melhores quando atendemos juntos. A presença física nas sessões de um colega que respeitamos, e com quem trabalhamos de forma alinhada, permite relembrar nossas posturas teóricas e compromissos éticos de uma forma enfática. Sabemos que, no cotidiano da prática clínica, é importante nos reconectarmos com estes aspectos em que acreditamos. Esperamos que 
este artigo inspire outros terapeutas a continuadamente repensarem suas práticas, a buscarem suporte junto a colegas de confiança e a se enxergarem como produtores de conhecimento.

\section{REFERÊNCIAS}

Andersen, T. (1999). Processos reflexivos. Rio de Janeiro: Instituto Noos.

Anderson, H. \& Goolishian, H. A. (1992). The client is the expert: A not-knowing approach to therapy. In S. McNamee \& K. J. Gergen (Eds.), Therapy as social construction (Inquiries in social construction series) (pp. 25-39). Thousand Oaks, CA: Sage.

Barreto, A. \& Grandesso, M. (2010). Community therapy: A participatory response to psychic misery. The International Journal of Narrative Therapy and Community Work, 4, 33-41.

Brinkmann, S. (2014). Languages of suffering. Theory \& Psychology, 24(5), 630-648. doi: $10.1177 / 0959354314531523$

Lock, A. \& Strong, T. (Eds.). (2012). Discursive perspectives on therapeutic practice. New York: Oxford University Press.

Gergen, K. J. (2009). Relational Being: Beyond self and community. London: Oxford University Press.

Gergen, K. J. \& Ness, O. (2016). Therapeutic practice as social construction. In M. O'Reilley \& J. N. Lester (Eds.), The Palgrave Handbook of Adult Mental Health (pp. 502-519). London: Palgrave Macmillan UK.

Guanaes, C. (2006). A construção da mudança em terapia de grupo: um enfoque construcionista social. Rio de Janeiro: Vetor.

Håkansson, C. (2015). The extended therapy room. Europe- an Journal of Psychotherapy \& Counselling, 17(4), 384-401. doi: 1080/13642537.2015.1094503

Harré, R. (2015). Positioning theory. In J. Martin, J. Sugarman, \& K. L. Slaney, The Wiley Handbook of theoretical and philosophical Psychology: Methods, approaches, and new directions for social sciences (pp. 263-276). Hoboken, NJ: Wiley-Blackwell.

Manfrim, A. F. N. \& Rasera, E. F. (2016). Diálogos entre o discurso construcionista social e a terapia social. Nova Perspectiva Sistêmica, 56, 34-48.

Martins, P. P. S., \& Guanaes-Lorenzi, C. (2017). Autorrevelação como recurso conversacional em terapia. In E. F. Rasera, K. Taverniers \& O. Vilches-Álvarez (Eds.) Construccionismo social en acción: Practicas inspiradoras en diferentes contextos (pp. 391-418). Chagrin Falls, OH: Taos Institute Publications.

McNamee, S. (2004). Therapy as social construction: Back to basics and forward toward challenging issues. In T. Strong \& D. Paré (Eds.), Furthering talk: Advances in the discursive therapies (pp. 1-28). New York: Kluwer Academic/Plenum Press.

O’Reilly, M., Kiyimba, N., \& Lester, J. N. (2018). Discursive psychology as a method of analysis for the study of couple and family therapy, Journal of Marital and Family Therapy, 44(3), 409-425. doi: 10.1111/jmft.12288.

Paula-Ravagnani, G. S, Guanaes-Lorenzi, C., \& Rasera. E. F. (2017). Use of theoretical models in Family therapy: focus on social constructionism. Paideia, 27(67), 84-92. doi: 10.1590/1982-43272767201710

Rober, Pus Elliott, Rus Buysse, Ang Loots, G., \& De Corte, K. (2008). Journal of Marital and Family Therapy, 34(3), 406-421. doi: 10.1111/j.1752-0606.2008.00080.x 
Sampson, E. E. (1993). Celebrating the Other: A dialogic account of human nature. Hertfordshire, UK: Harvester Wheatsheaf.

Seikkula, J., \& Olson, M. (2003). The open dialogue approach to acute psychosis: its poetics and micropolitics. Family Process, 42, 403-418. doi: 10.1111/j.1545-5300.2003.00403.x

Shotter, J. (2015). Tom Andersen, fleeting events, the bodily feelings they arouse in us, and the dialogical: Transitory understandings, and action guiding anticipations. Australian and New Zealand Journal of Family Therapy, 36(1), 72-87. doi: 10.1002/anzf.1087.

Vicente, A. T., Japur, M., César, A. B. C., Ruffino, C. M. C., \& Russo, R. (2015). The construction of the conversational context of the group. In E. F. Rasera (Ed.), Social constructionist perspectives on group work (pp. 6170). Chagrin Falls, OH: Taos Institute Publications.

White, M. (2012). Mapas da Prática Narrativa. Porto Alegre: Pacartes.

\section{PEDRO P. S. MARTINS}

É doutor e mestre em Psicologia pela Universidade de São Paulo e psicólogo pela Universidade Federal de Uberlândia. É membro associado do Taos Institute, no qual atua como parte do Conselho Latino-Americano. Atualmente, atua como psicólogo clínico na cidade de Uberlândia - MG, onde atende indivíduos, famílias e casais a partir de uma perspectiva construcionista social. É um dos coordenadores do Romã, um grupo terapêutico temático, que favorece o diálogo sobre amor e relacionamentos. Coordena também o curso "Construcionismo Social na Prática”, no qual anualmente oferece uma introdução aos principais conceitos teóricos e práticos relacionados à construção social. Além disso, é docente convidado na formação em Terapia Familiar do Instituto ConversAções, em Ribeirão Preto. Sua pesquisa e prática estão voltadas para o trabalho com famílias em contextos clínicos e de saúde mental. Atuou como pesquisador no Laboratório de Pesquisa e Estudo em Práticas Grupais da FFCLRP-USP e como colaborador no Programa de Atendimento às Famílias do Hospital-Dia de Psiquiatria do Hospital das Clínicas da USP de Ribeirão Preto. Em 2012 e 2015, foi pesquisador visitante na University of New Hampshire, Estados Unidos da América.

E-mail: pedropablomartins@gmail.com

\section{MARINA ARANTES}

É psicóloga e mediadora de conflitos. É graduada pela Universidade Federal de Uberlândia, onde atuou como co-supervisora de alunos trabalhando com populações vulneráveis em diferentes contextos. Como psicóloga clínica, ela atua com crianças, adultos e famílias em uma prática sensível às premissas construcionistas sociais sobre realidade e produção de sentidos. Está envolvida em diferentes contextos de formação, comprometidos com a disseminação das ideias construcionistas sociais: como professora no curso "Construcionismo Social na Prática”, financiado pelo Taos Institute, e como supervisora de outros terapeutas e alunos. Ela é cofundadora do Instituto Verso: Mediação de Conflitos, onde trabalha como mediadora, além de articular múltiplos contextos que têm por objetivo a propagação de formas alternativas de resolver e entender conflitos.

E-mail: marina.arantes.s@gmail.com 